\title{
THE EFFECT OF PHARMACEUTICAL INNOVATION ON THE FUNCTIONAL LIMITATIONS OF ELDERLY AMERICANS: EVIDENCE FROM THE 2004 NATIONAL NURSING HOME SURVEY
}

\author{
Frank R. Lichtenberg \\ Working Paper 17750 \\ http://www.nber.org/papers/w17750
NATIONAL BUREAU OF ECONOMIC RESEARCH
1050 Massachusetts Avenue
Cambridge, MA 02138
January 2012

This research was supported by Novartis. The sponsor placed no restrictions or limitations on data, methods, or conclusions, and had no right of review or control over the outcome of the research. I am grateful to Robert Kaestner and an anonymous referee for helpful comments on a previous version of this paper. The views expressed herein are those of the author and do not necessarily reflect the views of the National Bureau of Economic Research.

NBER working papers are circulated for discussion and comment purposes. They have not been peerreviewed or been subject to the review by the NBER Board of Directors that accompanies official NBER publications.

(C) 2012 by Frank R. Lichtenberg. All rights reserved. Short sections of text, not to exceed two paragraphs, may be quoted without explicit permission provided that full credit, including $(\mathbb{C}$ notice, is given to the source. 
The Effect of Pharmaceutical Innovation on the Functional Limitations of Elderly Americans: Evidence from the 2004 National Nursing Home Survey

Frank R. Lichtenberg

NBER Working Paper No. 17750

January 2012

JEL No. I12,L65,O33

\begin{abstract}
$\underline{\text { ABSTRACT }}$
I examine the effect of pharmaceutical innovation on the functional status of nursing home residents using cross-sectional, patient-level data from the 2004 National Nursing Home Survey. This was the first public-use survey of nursing homes that contains detailed information about medication use, and it contains better data on functional status than previous surveys.

Residents using newer medications and a higher proportion of priority-review medications were more able to perform all five activities of daily living (ADLs), controlling for age, sex, race, marital status, veteran status, where the resident lived prior to admission, primary diagnosis at the time of admission, up to 16 diagnoses at the time of the interview, sources of payment, and facility fixed effects.

The ability of nursing home residents to perform activities of daily living is positively related to the number of "new" (post-1990) medications they consume, but unrelated to the number of old medications they consume. If 2004 nursing home residents had used only old medications, the fraction of residents with all five ADL dependencies would have been 58\%, instead of 50\%. During the period 1990-2004, pharmaceutical innovation reduced the functional limitations of nursing home residents by between $1.2 \%$ and $2.1 \%$ per year.
\end{abstract}

Frank R. Lichtenberg

Columbia University

504 Uris Hall

3022 Broadway

New York, NY 10027

and NBER

frl1@columbia.edu 


\section{Introduction}

There has been a significant decline over time in the functional limitations of older people in the United States, and probably worldwide. This finding has been confirmed using multiple datasets, multiple measures of functional disability, and multiple research methodologies. For example, Costa (2000) found that functional limitation (difficulty walking, difficulty bending, paralysis, blindness in at least one eye, or deafness in at least one ear) in the United States fell at an average annual rate of $0.6 \%$ among men aged 50 to 74 from the early twentieth century to the early 1990s, and Manton, Gu, and Lamb (2006) found a significant rate of decline in the prevalence of chronic disability in the Medicare-enrolled population aged 65+ that accelerated from 1982 to 2004. The recent decline in disability has occurred despite the considerable increase in obesity. ${ }^{1}$

A number of factors may have contributed to the long-run decline in disability. It has been hypothesized that medical innovation in general, and pharmaceutical innovation in particular, have made important contributions to the decline in the functional limitations of older people. Costa (2000) argued that "increased efficacy of medical care” was one of the two main factors that could account for the long-term decline in functional disability at older ages. ${ }^{2}$ Experts convened at a 2001 National Institute of Aging-National Bureau of Economic Research workshop on disability decline noted that “there have been many 'high tech' medical advances that have improved health" (Woodbury (2001)). Three examples they cited were intensive treatment for heart disease, increased use of anti-inflammatory drugs for arthritis treatment, and “significant advances in both pharmacological and other treatment of mental illness." The experts agreed that "more research was recommended to better quantify the relative importance of [the] various factors" contributing to disability decline.

In this paper, I will examine the effect of pharmaceutical innovation on the functional status of nursing home residents using cross-sectional, patient-level data from the 2004 National Nursing Home Survey (NNHS). This was the first public-use survey of nursing homes that contains detailed information about medication use, and it contains better data on functional status than previous surveys. In particular, I will investigate whether nursing home residents

\footnotetext{
${ }^{1}$ The fraction of American adults that are obese (BMI greater than or equal to 30.0) increased from 22.9\% in 1988 94 to 34.3\% in 2005-6. http://www.cdc.gov/nchs/data/hestat/overweight/overweight_adult.htm\#table1

2 The second factor she cited is the decline in chronic disease rates.
} 
using newer drugs have higher functional status, controlling for multiple diagnoses and many other characteristics of residents and of the facilities where they reside. About 1.5 million Americans resided in nursing homes in 2004. Eighty-eight percent were 65 years and older; 45\% were 85 years and older. ${ }^{3}$

The 2004 NNHS consisted of a two-stage design with a probability sample of 1,500 nursing facilities in the first stage and up to 12 current residents from each facility in the second stage. This nationally representative sample survey was conducted by the Centers for Disease Control and Prevention's National Center for Health Statistics from August 2004 through January 2005. For 13,507 recipients, data were obtained on health status, medications taken, demographic characteristics, services received, and sources of payment. Data for the survey were obtained through personal interviews with facility administrators and designated staff who used administrative records to answer questions about the facilities, staff, services and programs, and medical records to answer questions about the residents.

The basic research design of the study is depicted in Figure 1. The NNHS contains information about the ability of the resident to perform various activities of daily living (ADLs). For each activity, the resident's ability is evaluated on an ordinal scale (from "independent” to “totally dependent”). We will estimate ordered probit models ${ }^{4}$ of the ability of an individual to perform activities of daily living.

The explanatory variables of primary interest are the characteristics of the medications used by the resident. ${ }^{5}$ One important attribute is the mean vintage (FDA approval year) of medications used. We hypothesize that the quality of new drugs tends to be higher than the quality of old drugs, and therefore that mean vintage is an indicator of the average quality of drugs consumed. Drugs that received "priority-review" status from the FDA may also be of higher quality than "standard-review" drugs, conditional on FDA approval year. ${ }^{6}$ As shown in Figure 1, we will control for a large set of nursing home resident attributes that are likely to

\footnotetext{
${ }^{3}$ http://www.cdc.gov/nchs/data/nnhsd/Estimates/nnhs/Estimates_Demographics_Tables.pdf\#Table01

4 The probit procedure calculates maximum likelihood estimates of regression parameters and the natural (or threshold) response rate for quantal response data from biological assays or other discrete event data. Probit analysis developed from the need to analyze qualitative (dichotomous or polytomous) dependent variables within the regression framework. Ordinary least squares (OLS) regression is inadequate when the dependent variable is discrete. Probit or logit analyses are more appropriate in this case. See Rodríguez (2010) for a discussion of the ordered probit model.

${ }^{5}$ The mean number of medications used by nursing home residents is nine.

6 The "effective vintage" of a standard-review drug may be older than that of a priority-review drug.
} 
influence his or her functional status, including detailed information about diagnoses, demographic characteristics (age, sex, race, marital status, etc.), and sources of payment.

We believe that heterogeneous pharmaceutical treatment of nursing home patients, controlling for their diagnoses, demographic characteristics, insurance coverage, facility, and other factors, is primarily due to physician practice variation. ${ }^{7}$ Wennberg (2004) argues that "unwarranted [treatment] variation — variation not explained by illness, patient preference, or the dictates of evidence-based medicine-is a ubiquitous feature of U.S. health care.” A large number of studies have documented the importance of unexplained variation in medical care in general and prescribing behavior in particular. Much of this literature focuses on regional variation in medical treatment, ${ }^{8}$ but a number of studies have shown that there is substantial treatment variation within narrowly-defined regions, health care organizations, and even facilities. Dick et al (2011) analyzed data on 994 women who were diagnosed with Ductal Carcinoma In Situ from 1985 through 2000 in Monroe County (New York) and the Henry Ford Health System (Detroit, MI). They found that "margin status and receipt of radiation therapy vary by surgeon," and "the extent of variation [by surgeon] and its contribution to long-term health outcomes are troubling." Kralewski et al (1999) found that, even within a single Minneapolis/St. Paul HMO during 1990, there were "wide variations in individual physician practice styles" in the amount of resources used to manage uncomplicated hypertension. Ketcham et al (2007) found that "patients treated by solo physicians were less likely to receive cardiac catheterization and angioplasty within a day of admission and more likely to die than other patients in the same hospital, even after a number of patient and physician characteristics were taken into account” (emphasis added). Data published by the New York State Department

\footnotetext{
${ }^{7}$ Data collected by Levy et al (2006) from eight nursing homes indicated that the mean number of physicians who come to a facility is 15; the mean number of beds in the eight facilities was 212. (The eight facilities were selected for case studies of physician practice models; no attempt was made to select a representative sample from which to draw statistical inferences.) The mean number of prescribers in a facility is presumably greater than 15 , since in some cases medications may also be prescribed by nursing home staff (medical directors) and advanced practice nurses. The mean number of registered nurses in a nursing home is 8 (http://www.cdc.gov/nchs/data/nnhsd/nursinghomefacilities2006.pdf).

${ }^{8}$ Some studies of regional variation have found no correlation across regions between measures of treatment intensity (e.g. per capita medical expenditure) and health outcomes. But Lichtenberg (2011a, 2011b, 2011c) provides evidence based on longitudinal state-level data from both the U.S. and Germany that states that adopted medical innovations (new drugs and/or advanced imaging procedures) more rapidly had larger improvements in health (higher longevity growth and/or slower disability growth), controlling for other determinants of health.
} 
of Health (1998) indicate that the risk-adjusted mortality rates of patients receiving coronary artery bypass surgery varied considerably across surgeons operating within the same hospital.

Health services researchers have identified a number of factors that explain some of the variation in individual physician practice styles, including physician gender, practice size, specialty, and membership in professional organizations.

Physician gender. DeSalvo et al (2000) reported “wide variation...in assignment of reappointment interval with mean return intervals...ranging from 2.2 to 20.5 weeks. Sex was a significant provider independent variable...Female providers assigned earlier reappointment intervals for their patients.” Kuo et al (2011) examined the effect of physician characteristics on provision of recommended care practices for children with special health care needs among primary care physicians in Arkansas. They found that female physicians spent more time with patients and were more likely to provide community referrals.

Practice size. Epstein et al (1983) studied the records of 351 hypertensive patients cared for by 30 internists in group or solo private practice to investigate whether group size influences the number of tests ordered for ambulatory patients. They found that patients of physicians who were members of large groups received twice as many tests as patients of physicians in small groups or in solo practice. These effects were independent of the patient's age and sex, the year the physician graduated from medical school, and the availability of testing machinery at the practice site. Kuo et al (2011) found that solo and 2-person practice was associated with recommended care practices, including written care plan.

Physician specialty. Greenfield et al. (1992) found that cardiologists and endocrinologists had higher levels of resource utilization (hospitalizations, annual office visits, prescription drugs, and common tests and procedures) than physicians practicing family medicine and internal medicine, controlling for patient mix and other factors.

Membership in professional organizations. Chung et al (2011) found that Medicare beneficiaries who were treated by American Society for Surgery of the Hand member surgeons receive internal fixation for distal radius fractures (DRFs) at a significantly higher rate than do patients of other physicians. 
These factors explain some of the variation in individual physician practice styles, but most of the variation is unexplained. For example, Kralewski et al (1999) found that "culture and structural variables explained only 8 percent of the variance in resource use.”

\section{Measurement}

Functional status. The survey obtained data on the ability of residents to perform the following five Activities of Daily Living (ADLs): (1) transferring (to/from: bed, chair, wheelchair, standing position); (2) dressing; (3) eating; (4) using the toilet; and (5) bathing. For each of these activities, the survey determined whether (1) the resident could perform the activity independently; (2) the resident requires supervision; (3) the resident requires limited assistance; (4) the resident requires extensive assistance; or (5) the resident is totally dependent. ${ }^{9}$ Table 1 shows the percent distribution of nursing home residents, according to type of assistance required with each activity of daily living. It also shows the percent distribution of nursing home residents, by number of ADL dependencies (i.e., the number of activities for which the resident was not independent). Half of residents had five ADL dependencies (i.e., they could not perform any of the five ADLs independently); 78\% had 4 or more ADL dependencies. Two-thirds of residents were able to eat independently or with supervision, but only $8 \%$ were able to bathe independently or with supervision.

Medication attributes. The survey also obtained data on all medications used by the resident. Nursing home residents tend to use many medications; the mean number of medications used is nine. We identified the active ingredients of all of the medications used by each resident. We used data provided by the FDA (http://www.fda.gov/Drugs/InformationOnDrugs/ucm079750.htm) to determine two attributes of each active ingredient: (1) the year in which the FDA first approved a product containing that active ingredient (we refer to this year as the "vintage" of the active ingredient); and (2) whether any products containing that active ingredient were approved on a priority-review (as opposed to standard-review) basis. The FDA grants Priority Review designation to drugs that are believed to offer major advances in treatment, or provide a treatment where no adequate therapy exists,

\footnotetext{
${ }^{9}$ Previous surveys (e.g. the 1999 NNHS) only reported whether or not the resident required at least some assistance.
} 
and Standard Review designation to drugs believed to offer at most, only minor improvement over existing marketed therapies. ${ }^{10}$ Thus, although the vintage (FDA approval year) of a standard-review drug may be greater than that of an earlier drug, its "effective vintage” may not be greater.

The NNHS provided data on N_RX $\mathrm{ia}_{\mathrm{ia}}$ : the total number of medications used by resident $\mathrm{i}$ that contained active ingredient a $(a=1, \ldots, 800)$. From the Drugs@FDA database, we constructed the following variables:

FDA_YEAR $_{\mathrm{a}}=$ the year in which the FDA first approved a product containing active ingredient a

POST1980 $_{\mathrm{a}}=1$ if FDA_YEAR $>1980$

$=0$ otherwise

POST1990a $_{\mathrm{a}}=1$ if FDA_YEAR $>1990$

$=0$ otherwise

PRIORITY $_{\mathrm{a}}=1$ if any products containing active ingredient a were approved on a priorityreview (as opposed to standard-review) basis $=0$ otherwise

We combined the NNHS medication data with the FDA ingredient attribute data to construct the following variables characterizing the distribution of medications used by each nursing home resident:

\footnotetext{
VINTAGE $_{\mathrm{i}}=\left(\Sigma_{\mathrm{a}} \mathrm{N}_{-} \mathrm{RX}_{\mathrm{ia}}\right.$ FDA_YEAR $\left.\mathrm{a}\right) / \Sigma_{\mathrm{a}} \mathrm{N} \_\mathrm{RX}$ ia $=$ the (weighted) mean vintage of medications used by resident $\mathrm{i}$

POST1980\% $\%_{\mathrm{i}}=\left(\Sigma_{\mathrm{a}} \mathrm{N}_{-} \mathrm{RX}_{\mathrm{ia}}\right.$ POST1980 $) / \Sigma_{\mathrm{a}} \mathrm{N}_{\mathrm{a}} \mathrm{RX}_{\mathrm{ia}}=$ the fraction of medications used by resident $\mathrm{i}$ that contained active ingredients approved after 1980

POST1990\% $\%_{i}=\left(\Sigma_{a} N_{-} R_{i a}\right.$ POST1990a $) / \Sigma_{a} N_{-} R_{i a}=$ the fraction of medications used by resident $\mathrm{i}$ that contained active ingredients approved after 1990

PRIORITY\% $\%_{\mathrm{i}}=\left(\Sigma_{\mathrm{a}}{\mathrm{N} \_R X_{\mathrm{ia}}}_{\text {PRIORITY }}\right)_{\mathrm{a}} / \Sigma_{\mathrm{a}} \mathrm{N} \_\mathrm{RX}_{\mathrm{ia}}=$ the fraction of medications used by resident $\mathrm{i}$ that contained active ingredients approved on a priority-review (as opposed to standard-review) basis

N_RX $\mathrm{R}_{\mathrm{i}}=\Sigma_{\mathrm{a}} \mathrm{N} \_\mathrm{RX}_{\mathrm{ia}}=$ the total number of medications used by resident $\mathrm{i}$

N_RX_NEW ${ }_{\mathrm{i}}=\Sigma_{\mathrm{a}}{\mathrm{N} \_R X_{\mathrm{i}}}_{\mathrm{a}}$ POST1990 $\mathrm{a}=$ the total number of "new" (post-1990) medications used by resident $\mathrm{i}$

N_RX_OLD ${ }_{\mathrm{i}}=\Sigma_{\mathrm{a}}$ N_RX $\mathrm{ia}\left(1-\mathrm{POST} 1990_{\mathrm{a}}\right)$ = the total number of “old” (pre-1991) medications used by resident $\mathrm{i}$
}

10

http://www.fda.gov/forconsumers/byaudience/forpatientadvocates/speedingaccesstoimportantnewtherapies/ucm128 291.htm\#priorityreview 
We will estimate several models to investigate how the characteristics of medications used affects the functional status of nursing home residents. The first model will be of the following form:

HEALTH $_{\mathrm{i}}=\beta$ VINTAGE $_{\mathrm{i}}+\gamma$ PRIORITY\% $_{\mathrm{i}}+\pi{\mathrm{N} \_R X_{i}} \rho \mathrm{Z}_{\mathrm{i}}+\varepsilon_{\mathrm{i}}$

Six indicators of HEALTH will be used: the number of ADLs which the resident can perform independently (N_INDEP; N_INDEP $=0,1, \ldots, 5)$ and indicators of the extent of assistance required for each ADL. ${ }^{11}$ The variable $\mathrm{Z}$ in eq. (1) represents a vector of a large number of other (non-medication-related) characteristics of the resident, whose elements will be described below. We hypothesize that $\beta>0$ : residents who use newer drugs will tend to be in better health, ceteris paribus. We also hypothesize that $\gamma>0$ : conditional on mean vintage, the greater the fraction of drugs that were priority-review drugs, the better the health of the consumer, since standardreview drugs are similar to older drugs. We are agnostic as to the sign of $\pi$. It would not be surprising if this coefficient were negative, i.e. if residents who consumed more medications were in worse health, since greater use of medical care (including prescription drugs) is often a marker for greater unobserved illness severity.

Eq. (1) is based on the implicit hypothesis that the effect of drug vintage on health status is linear. This rather strong assumption can be relaxed by estimating the following alternative model:

HEALTH $_{i}=\beta_{1}$ POST1980\% $_{i}+\beta_{2}$ POST1990\% $_{i}+\gamma$ PRIORITY\% $\%_{i}+\pi$ N_RX $_{i}+\rho Z_{i}+\varepsilon_{i}$

In this model, drugs approved before 1980 serve as the reference group. $\beta_{1}$ is an estimate of the difference between the health effects of post-1980 drugs and pre-1981 drugs; $\beta_{2}$ is an estimate of the difference between the health effects of post-1990 drugs and pre-1991 drugs; and $\left(\beta_{1}+\beta_{2}\right)$ is an estimate of the difference between the health effects of post-1990 drugs and pre-1981 drugs.

In both of the preceding equations, the resident's health is assumed to depend on the “quality” (vintage) and quantity of medications consumed in an additive fashion. However,

\footnotetext{
${ }^{11}$ These will be coded as follows: 4 = independent; 3 = supervision; 2 = limited assistance; 1 = extensive assistance; $0=$ total dependence.
} 
health may depend on the interaction between quality and quantity. ${ }^{12}$ The following model allows for this interaction:

HEALTH $_{i}=\alpha_{1}$ N_RX_NEW $+\alpha_{2}$ N_RX_OLD ${ }_{i}+\gamma$ PRIORITY\% $\%_{i}+\rho Z_{i}+\varepsilon_{i}$

We hypothesize that $\alpha_{1}>\alpha_{2}$ : the effect on health of an increase in the number of new medications is larger than the effect on health of an increase in the number of old medications. ${ }^{13}$

Demographic variables. We will control for single-year-of-age by sex, race, marital status, veteran status, and where the resident lived prior to admission.

Diagnosis variables. We will control for the primary diagnosis at the time of admission by including fixed primary-admission-diagnosis effects at the 2-digit ICD9 level. We also control for up to 16 diagnoses at the time of the interview by including dummy variables for each 2-digit ICD9 disease. If a resident had 5 diagnoses (comorbidities) at the time of the interview, five of these dummy variables would be equal to 1 , and the remainder would be zero.

Diseases of the circulatory system were the leading primary diagnoses among nursing home residents at admission (23.7\%) and at the time of interview (25\%). Mental disorders were the second leading primary diagnoses among residents at admission (16.4\%), as well as at the time of interview (21.9\%). Fourteen percent of residents had a primary admission diagnosis for diseases of the nervous system and sense organs, and $16.5 \%$ had that primary diagnosis at the time of interview.

Sources of payment. We will include dummy variables for each of the following sources of payment: private health insurance; life care; Self/Private pay/out-of-pocket; Medicare (including Medicare HMO); Medicaid (including Medicaid HMO); Welfare or other government assistance; Department of Veterans Affairs; and Other payment source.

Facility fixed effects. All models will include 1125 facility fixed effects. Due to the inclusion of these fixed effects, each nursing home resident is being compared with other residents of the same facility. Inclusion of these fixed effects will correct for systematic biases in reporting by facility administrators, e.g. about functional limitations of residents.

\footnotetext{
${ }^{12}$ Quality will matter more if the quantity is large.

${ }^{13}$ However, it might be the case that that $0>\alpha_{1}>\alpha_{2}$.
} 
Unfortunately, the NNHS does not provide information about other potential determinants of functional status, such as the resident's income, wealth, or educational attainment. However, these other potential determinants are likely to be controlled for, to an important extent, by factors included in the model, such as race, diagnoses, and sources of payment. The facility fixed effects are also likely to control for a substantial amount of variation in socioeconomic status (SES), since SES is likely to play an important role in the "assignment" of residents to facilities.

Table 2 shows mean values of the medication attribute variables, by race (black vs. not black) of resident. These data suggest that there is little or no correlation between medication attributes and SES. Medication attributes are also uncorrelated with sources of payment.

\section{Descriptive statistics}

Table 3 shows descriptive statistics on medication attributes. Table 4 shows the number of patients in the 2004 National Nursing Home Survey using prescription medicines, by class of drug.

Table 5 shows the top 40 medications used by 2004 National Nursing Home Survey respondents, ranked by the number of residents using the medication. The "FDA Approval Year" is the first year in which a product containing an ingredient was approved, according to the Drugs@FDA database. Some drugs are certainly older than this calculation implies. For example, according to the Merriam-Webster Dictionary, the first known use of the term "aspirin" was in 1899. ${ }^{14}$ The Drugs@FDA database does not provide reliable estimates of the vintage of very old drugs (those that existed before the FDA was established in 1938). It is likely that the variables POST1980\% and POST1990\% are measured more reliably than the VINTAGE variable.

Twenty-nine percent of 2004 nursing home residents were male, 8\% were veterans, and $10 \%$ were black. Sources of payment are shown in Table $6 .{ }^{15}$

\footnotetext{
${ }^{14}$ http://www.merriam-webster.com/dictionary/aspirin

${ }^{15}$ There can be multiple payment sources. Medicare's coverage of nursing home care is quite limited. Medicare covers up to 100 days of "skilled nursing care" per illness, but there are a number of requirements that must be met before the nursing home stay will be covered. http://seniorjournal.com/NEWS/Medicare/2008/8-01-18SenCitNeed2Know.htm A life-care fee or "founder's fee" is paid either monthly or as a lump sum under an agreement with a retirement home. http://www.irs.gov/publications/p502/ar02.html\#en_US_publink1000178969
} 


\section{Empirical results}

Estimates of selected coefficients from the first model of the functional status of nursing home residents (eq. (1)) are shown in Table 7. As noted earlier, all models include dummy variables for single-year-of-age by sex, race, marital status, veteran status, where the resident lived prior to admission, primary diagnosis at the time of admission, up to 16 diagnoses at the time of the interview, sources of payment, and facility fixed effects.

The dependent variable of the first model (model 1a) in Table 7 is the number of ADLs the resident could perform independently. As we hypothesized, the coefficients on VINTAGE and PRIORITY\% are both positive and highly significant. Residents using newer medications, and medications approved on a priority-review basis, were able to perform more activities of daily living independently, ceteris paribus. Recall that the FDA considers standard-review drugs (those not granted priority review) to be therapeutically similar to previously-approved drugs. The fact that the ratio of the PRIORITY\% coefficient to the VINTAGE coefficient is 22.6 suggests that standard-review drugs are similar to drugs approved 22.6 years earlier, on average.

The coefficient on the number of medications consumed (N_RX) is also positive and highly significant: residents consuming more medications were able to perform more activities of daily living independently. This is somewhat surprising since, as noted earlier, greater use of medical care (including prescription drugs) is often a marker for greater unobserved illness severity.

In the remaining five models (models 1b-1f) of Table 7, the dependent variables are indexes of the ability of residents to perform each of the five activities of daily living (transferring, dressing, etc.). In all five models, all three of the medication coefficients are positive and highly significant. Residents using newer medications, a higher proportion of priority-review medications, and more medications were more able to perform all five activities of daily living.

The estimates in Table 7 are from models that include facility fixed effects. We also estimated models that included a set of observable facility characteristics (dummy variables for 
nursing home ownership type, bedsize, and metropolitan area status ${ }^{16}$ ) instead of facility fixed effects, and models that included neither facility characteristics nor facility fixed effects. Estimates of the VINTAGE and PRIORITY\% coefficients from these models and models with facility fixed effects are shown in Table 8. In models 1-3 of Table 8, the dependent variable is the number of ADLs the resident could perform independently. Model 1 includes neither facility characteristics nor facility fixed effects (but all of the other covariates enumerated above). Model 2 includes facility characteristics, and model 3 includes facility fixed effects. Both the VINTAGE and the PRIORITY\% coefficients are positive and highly significant in all three models. The estimates of models 1 and 2 are quite similar: controlling for facility characteristics has almost no effect on these coefficients. But controlling for facility fixed effects significantly increases the magnitude of both coefficients: the VINTAGE coefficient is 55\% larger in model 3 than it is in model 1, and the PRIORITY\% coefficient is 34\% larger. Models 4-18 of Table 8 show that we obtain similar results when we analyze the other dependent variables: the VINTAGE and PRIORITY\% coefficients are positive and highly significant when we don't control for facility fixed effects (whether or not we control for facility characteristics), but are larger when we control for facility fixed effects. Since the facility fixed effects are likely to control for important determinants of measured functional status (e.g. the socioeconomic status of residents, unmeasured quality of healthcare providers, and biases in facility survey responses), we believe that models including facility fixed effects are the most reliable, and these fixed effects will be included in the models discussed in the remainder of this article.

Table 9 presents estimates of eq. (2), in which the VINTAGE variable is replaced by POST1980\% and POST1990\%. In all six models, the coefficients on all four medication variables are positive and significant. These estimates indicate that post-1980 medications reduce functional limitations more than pre-1981 medications, and that post-1990 medications reduce functional limitations more than pre-1991 medications. Moreover, the difference between the effects of post-1990 medications and medications approved in the 1980s is larger than the difference between medications approved in the 1980s and medications approved before 1981.

\footnotetext{
${ }^{16}$ There are two ownership status categories (for-profit vs. all others (private and gov't not-for-profit)), four bedsize categories (3-49 beds, 50-99 beds, 100-199 beds, and 200+ beds), and three metropolitan area status categories (metropolitan, micropolitan, and neither).
} 
Table 10 presents estimates of eq. (3), in which there are three medication variables: the number of “new” (post-1990) medications (N_RX_NEW), the number of “old” (pre-1991) medications (N_RX_OLD), and the fraction of (all) medications that were granted priorityreview (PRIORITY\%). In all six models, the coefficient on N_RX_NEW is positive and highly significant. The coefficient on N_RX_OLD is insignificant in four of the six models. It is positive and significant in only one model (model 3d, ability to eat), and in this case, it is only 1/7 as large as the coefficient on N_RX_NEW. This signifies that, in general, the ability of nursing home residents to perform activities of daily living is positively related to the number of new medications they consume, but unrelated to the number of old medications they consume. The positive coefficients on the total number of medications (N_RX) in eqs. (1) and (2) (Tables 3 and 4) was solely attributable to new medications.

All of the estimates reported so far have attempted to assess the impact of pharmaceutical innovation in general on the functional limitations of nursing home residents. Assessing the impact of specific types of pharmaceutical innovation (i.e., innovation in specific classes of drugs) is also worthwhile. If we had a much larger sample of patients, we could accomplish this by including characteristics (e.g. vintage) of multiple classes of drugs in a single model. But most patients take drugs in only a few classes, so including characteristics of multiple classes of drugs in a single model would severely limit our sample size. Therefore, we have estimated versions of eq. (3) separately for the five most highly utilized drug classes shown in Table 4.

These estimates are shown in Table $11 .^{17}$ We report estimates of six models in this table. In all of these models, the dependent variable is the number of ADLs the resident could perform independently, and the explanatory variables are: the patient's number of post-1980 medications within the drug class, the patient's number of pre-1981 medications within the drug class, and the fraction of the patient's medications within the drug class that were granted priority review. Model 1 in Table 11 shows estimates based on data on all medications. These estimates are consistent with the estimates presented in Table 10 (which defined new drugs as post-1990 drugs). Models 2-6 in Table 11 show estimates based on each of the five drug classes. In 3 out of 5 classes (metabolic/nutrients, cardiovascular-renal drugs, and central nervous system drugs),

\footnotetext{
${ }^{17}$ The number of observations for each drug class shown in Table 11 is lower than the number of patients using each drug class shown in Table 4 because the FDA approval years of some drugs could not be determined.
} 
the coefficient on the number of post-1980 medications is positive and highly significant, and the coefficient on the number of pre-1981 medications is not significant at the $5 \%$ level. In a fourth class (gastrointestinal agents), the coefficient on the number of post-1980 medications is insignificant, and the coefficient on the number of pre-1981 medications is negative and significant; the difference between the two coefficients is positive and presumably significant ${ }^{18}$ (as it is in models 2, 3, and 5). In the fifth class (relief of pain drugs), the coefficient on the number of post-1980 medications is again larger than the coefficient on the number of pre-1981 medications, but the difference appears to be insignificant. These results indicate that the estimates presented in Tables 7-10 do not merely reflect the impact of innovation in a small minority of drug classes.

Now I will use the estimates in Table 10 to estimate how much higher the functional limitations of 2004 nursing home residents would have been if only pre-1991 medications had been used. As noted earlier, in 2004 the mean values of N_RX_NEW and N_RX_OLD were 3.63 and 5.51, respectively, and the mean value of N_RX was $9.14(=3.63+5.51)$. Suppose that 2004 nursing home residents had consumed the same number of medications, but that none of those medications were post-1990 medications: N_RX_NEW = 0 and N_RX_OLD = 9.14. Fourteen years earlier (in 1990), none of the medications could have been post-1990 medications. The coefficients on N_RX_NEW and N_RX_OLD in Table 10 allow us to estimate how much higher the functional limitations of 2004 nursing home residents would have been had they used zero new medications and 9.14 old medications instead of 3.63 new medications and 5.51 old medications. The predicted probability of being totally dependent is

$$
\text { prob_depend_pred } \left.=\mathrm{F}\left[\mathrm{F}^{-1} \text { (prob_depend_actual }\right)+3.63\left(\alpha_{1}-\alpha_{2}\right)\right]
$$

where prob_depend_actual = the actual probability of being totally dependent (shown in Table 1); $\alpha_{1}=$ the coefficient on N_RX_NEW in eq. (3); $\alpha_{2}=$ the coefficient on N_RX_OLD in eq. (3); F( ) is the standard normal cumulative distribution; and $\mathrm{F}^{-1}(\mathrm{)}$ ) is the inverse of the standard normal cumulative distribution.

The results of these calculations are shown in Figure 2. The estimates imply that the functional limitations of 2004 nursing home residents would have been considerably greater if only pre-1991 medications had been used. For example, we estimate that 33\% of residents

\footnotetext{
${ }^{18}$ The software we use (the SAS Probit procedure) does not allow us to perform tests of the significance of differences between parameter estimates.
} 
would have been totally dependent to get dressed, instead of $25 \%$ of residents. ${ }^{19}$ Since only pre1991 medications were used in 1990, (1/14) * $\ln$ (prob_depend_actual/prob_depend_pred) is an estimate of the average annual rate of decline of functional limitation due to pharmaceutical innovation during the period 1990-2004. These estimates, by ADL, are shown in Table 12. During the period 1990-2004, pharmaceutical innovation is estimated to have reduced the functional limitations of nursing home residents by between $1.2 \%$ and $2.1 \%$ per year.

\section{Summary and conclusions}

There has been a significant decline over time in the functional limitations of older people in the United States, and probably worldwide. Previous investigators have hypothesized that medical innovation in general, and pharmaceutical innovation in particular, has made important contributions to the decline in the functional limitations of older people. In this paper, I have examined the effect of pharmaceutical innovation on the functional status of nursing home residents using cross-sectional, patient-level data from the 2004 National Nursing Home Survey. This was the first public-use survey of nursing homes that contains detailed information about medication use, and it contains better data on functional status than previous surveys.

I found that residents using newer medications and a higher proportion of priority-review medications were more able to perform all five activities of daily living, controlling for age, sex, race, marital status, veteran status, where the resident lived prior to admission, primary diagnosis at the time of admission, up to 16 diagnoses at the time of the interview, sources of payment, and facility fixed effects.

The ability of nursing home residents to perform activities of daily living is positively related to the number of "new" (post-1990) medications they consume, but unrelated to the number of old medications they consume. We estimated how much higher the functional limitations of 2004 nursing home residents would have been had they used old medications instead of new medications. We estimate that the fraction of nursing home residents with all five ADL dependencies (number of activities for which the resident is not independent) would have been 58\%, instead of 50\%. During the period 1990-2004, pharmaceutical innovation is

\footnotetext{
${ }^{19}$ We also estimate that the fraction of nursing home residents with all five ADL dependencies (number of activities for which the resident is not independent) would have been $58 \%$, instead of $50 \%$.
} 
estimated to have reduced the functional limitations of nursing home residents by between 1.2\% and $2.1 \%$ per year.

Unfortunately, the NNHS does not provide information about some potential determinants of functional status, such as the resident's income, wealth, or educational attainment. However, these other potential determinants are likely to be controlled for, to an important extent, by factors included in the model, such as race, diagnoses, and sources of payment. The facility fixed effects are also likely to control for a substantial amount of variation in socioeconomic status (SES), since SES is likely to play an important role in the "assignment” of residents to facilities. Also, analysis of data by race suggested that there is little or no correlation between medication attributes and SES. 


\section{References}

Chung KC, Shauver MJ, \& Yin H. (2011), “The relationship between ASSH membership and the treatment of distal radius fracture in the United States Medicare population,” J Hand Surg Am. 36(8), Aug: 1288-93. Epub 2011 Jun 29.

Costa, D. L. (2002), Changing Chronic Disease Rates and Long-Term Declines in Functional Limitation Among Older Men, Demography 39 (1), February, pp. 119-137.

DeSalvo, K., Bowdish, B., Alper, A, Grossman, D, \& Merrill, W (2000), Physician Practice Variation in Assignment of Return Interval, Arch Intern Med. 160:205-208. http://archinte.amaassn.org/cgi/content/abstract/160/2/205

Dick, A., et al (2011) "Comparative Effectiveness of Ductal Carcinoma In Situ Management and the Roles of Margins and Surgeons,” JNCI J Natl Cancer Inst 103 (2): 92-104.

Epstein AM, Begg CB, \& McNeil BJ. (1983), “The effects of group size on test ordering for hypertensive patients,” N Engl J Med. 309(8), 464-8, Aug 25.

Greenfield, S., et al (1992), "Variations in Resource Utilization among Medical Specialties and Systems of Care: Results from the Medical Outcomes Study," Journal of the American Medical Association 267 (12): 1624-1630.

Jones AL, Dwyer LL, Bercovitz AR, \& Strahan GW (2009). The National Nursing Home Survey: 2004 overview. National Center for Health Statistics. Vital Health Stat 13(167), http://www.cdc.gov/nchs/data/series/sr_13/sr13_167.pdf

Ketcham, JD., Baker, LC, \& MacIsaac, D (2007), "Physician Practice Size and Variations in Treatments and Outcomes: Evidence from Medicare Patients with AMI," Health Affairs, 26, no. 1 (2007): 195-205, http://content.healthaffairs.org/content/26/1/195.full

Kralewski JE, et al (1999), “The effects of medical group practice organizational factors on physicians' use of resources,” J Healthc Manag. 44(3), May-Jun; 167-82; discussion 182-3.

Krein, SL, Hofer, TP, Kerr, EA, \& Hayward, RA (2002), Whom Should We Profile? Examining Diabetes Care Practice Variation among Primary Care Providers, Provider Groups, and Health Care Facilities, Health Serv Res. 37(5), October: 1159-1180.

http://www.ncbi.nlm.nih.gov/pmc/articles/PMC1464024/

Kuo, DZ, et al (2011), “Individual and Practice Characteristics Associated With Physician Provision of Recommended Care for Children With Special Health Care Needs,” Clinical Pediatrics 50 (8), 704-711, August. 
Levy, C, et al (2006), "Physician Practices in Nursing Homes: Final Report," Prepared for Office of Disability, Aging and Long-Term Care Policy, Office of the Assistant Secretary for Planning and Evaluation, U.S. Department of Health and Human Services, http://aspe.hhs.gov/daltcp/reports/2006/phypracfr.htm

Lichtenberg, FR. (2011a), “The quality of medical care, behavioral risk factors, and longevity growth,” International Journal of Health Care Finance and Economics 11(1), March 2011, 1-34.

Lichtenberg, FR. (2011b), "Has pharmaceutical innovation reduced Social Security Disability growth?,” International Journal of the Economics of Business 18 (2), 293-316.

Lichtenberg, FR. (2011c), "The contribution of pharmaceutical innovation to longevity growth in Germany and France, 2001-2007,” PharmacoEconomics, forthcoming.

Manton KG, Gu X, \& Lamb VL (2006). Change in chronic disability from 1982 to 2004/2005 as measured by long-term changes in function and health in the US elderly population. Proceedings of the National Academy of Sciences of the United States of America 103(48):18374-18379.

McCullagh, P. (1980). Regression models for ordinal data. Journal of the Royal Statistical Society, Series B (Methodological), 42, 109-142.

New York State Department of Health (1998), Coronary Artery Bypass Surgery in New York State, http://www.health.ny.gov/statistics/diseases/cardiovascular/heart_disease/docs/19941996_adult_cardiac_surgery.pdf

Rodríguez, G (2010). Models for Ordinal Response Data, http://data.princeton.edu/wws509/notes/c6s5.html

Wennberg, J (2004), "Practice Variations and Health Care Reform: Connecting the Dots," Health Affairs, October 7, http://www.pnhp.org/news/2004/october/practice_variations_.php

Woodbury, R (2001), "Disability Decline: What We Know; and What We'd Like to Know," NIA-NBER Workshop Summary, November 30, http://www.nia.nih.gov/NR/rdonlyres/B08CB3BE-71EB-4DD4-A8660E94E9F6A96C/2303/disabilitydecline_11_30_01.pdf 
Figure 1

Basic research design

Medication attributes

- $\quad$ Mean vintage (FDA approval year) of rx's

- $\quad \%$ of rx's that are for priority-review drugs

- Number of rx's for "new” drugs

- Number of rx's for “old” drugs

\section{Patient diagnoses}

- Current primary diagnosis

- Current secondary diagnoses (up to 16)

$\underline{\text { Facility fixed effects }}$

Demographic variables

- Age

- Gender

- Marital status

- Veteran status

- Race

- Where staying before entering this facility

- $\quad$ Sources of payment (Private insurance, Medicare, Medicaid, Self-pay, Welfare, VA)
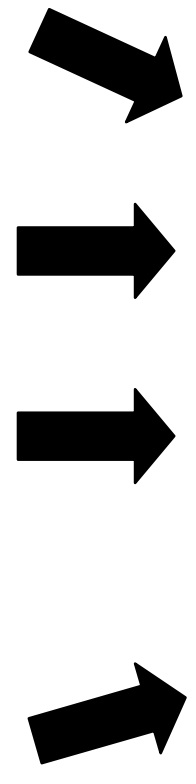

$\underline{\text { Indicators of functional status }}$

Ability to perform Activities of Daily Living (ADLs):

- transferring (to/from: bed, chair, wheelchair, standing position)

- dressing

- eating

- using the toilet

- bathing

For each of these activities, is the subject's self-performance:

- independent

- $\quad$ requires supervision

- requires limited assistance

- requires extensive assistance

- $\quad$ is totally dependent 
Table 1

Percent distribution of nursing home residents, according to extent of assistance required with activities of daily living

\begin{tabular}{|l|c|c|c|c|c|}
\hline & \multicolumn{5}{|c|}{ Activity } \\
\hline Extent of assistance required & transfer & dress & eat & toilet & bath \\
\hline Independent & $22 \%$ & $11 \%$ & $44 \%$ & $18 \%$ & $2 \%$ \\
\hline Supervision & $7 \%$ & $7 \%$ & $23 \%$ & $6 \%$ & $6 \%$ \\
\hline Limited assistance & $20 \%$ & $22 \%$ & $10 \%$ & $17 \%$ & $9 \%$ \\
\hline Extensive assistance & $28 \%$ & $35 \%$ & $9 \%$ & $28 \%$ & $46 \%$ \\
\hline Total dependence & $22 \%$ & $25 \%$ & $15 \%$ & $31 \%$ & $37 \%$ \\
\hline TOTAL & $100 \%$ & $100 \%$ & $100 \%$ & $100 \%$ & $100 \%$ \\
\hline
\end{tabular}

\begin{tabular}{|l|r|}
\hline $\begin{array}{l}\text { Number of ADL dependencies } \\
\text { (number of activities for which } \\
\text { the resident is not independent) }\end{array}$ & $\begin{array}{l}\text { Percentag } \\
\text { e of } \\
\text { nursing } \\
\text { home } \\
\text { residents }\end{array}$ \\
\hline 0 & $2 \%$ \\
\hline 1 & $7 \%$ \\
\hline 2 & $7 \%$ \\
\hline 3 & $6 \%$ \\
\hline 4 & $28 \%$ \\
\hline 5 & $50 \%$ \\
\hline TOTAL & $100 \%$ \\
\hline
\end{tabular}

$\mathrm{N}=12,357$. 


\section{Table 2}

Mean values of the medication attribute variables, by race (black vs. not black) of resident

\begin{tabular}{|l|c|c|}
\hline & $\begin{array}{c}\text { Black or African American } \\
(\mathrm{N}=1406)\end{array}$ & $\begin{array}{c}\text { Not Black or African American } \\
(\mathrm{N}=12,101)\end{array}$ \\
\hline $\begin{array}{l}\text { weighted mean vintage of } \\
\text { medications used (VINTAGE) }\end{array}$ & 1980.3 & 1980.5 \\
\hline $\begin{array}{l}\text { fraction of medications used } \\
\text { that contained active } \\
\text { ingredients approved after 1980 } \\
\text { (POST1980\%) }\end{array}$ & $59 \%$ & $57 \%$ \\
\hline $\begin{array}{l}\text { fraction of medications used } \\
\text { that contained active } \\
\text { ingredients approved after 1990 } \\
\text { (POST1990\%) }\end{array}$ & $39 \%$ & $40 \%$ \\
\hline $\begin{array}{l}\text { fraction of medications used } \\
\text { that contained active } \\
\text { ingredients approved on a } \\
\text { priority-review (as opposed to } \\
\begin{array}{l}\text { standard-review) basis } \\
\text { (PRIORITY\%) }\end{array}\end{array}$ & $51 \%$ & $49 \%$ \\
\hline
\end{tabular}


Table 3

Descriptive statistics on medication attributes

\begin{tabular}{|c|c|c|c|c|}
\hline & mean & std. dev. & minimum & maximum \\
\hline $\begin{array}{l}\text { weighted mean vintage } \\
\text { of medications used } \\
\text { (VINTAGE) }\end{array}$ & 1980.47 & 7.26 & 1911 & 2006 \\
\hline $\begin{array}{l}\text { fraction of medications } \\
\text { used that contained } \\
\text { active ingredients } \\
\text { approved on a priority- } \\
\text { review (as opposed to } \\
\text { standard-review) basis } \\
\text { (PRIORITY\%) }\end{array}$ & $49 \%$ & $20 \%$ & $0 \%$ & $100 \%$ \\
\hline $\begin{array}{l}\text { fraction of medications } \\
\text { used that contained } \\
\text { active ingredients } \\
\text { approved after } 1980 \\
\text { (POST1980\%) }\end{array}$ & $57 \%$ & $22 \%$ & $0 \%$ & $100 \%$ \\
\hline $\begin{array}{l}\text { fraction of medications } \\
\text { used that contained } \\
\text { active ingredients } \\
\text { approved after } 1990 \\
\text { (POST1990\%) } \\
\end{array}$ & $40 \%$ & $22 \%$ & $0 \%$ & $100 \%$ \\
\hline $\begin{array}{l}\text { the total number of } \\
\text { medications used } \\
\text { (N_RX) }\end{array}$ & 9.02 & 4.16 & 0 & 30 \\
\hline $\begin{array}{l}\text { the total number of } \\
\text { “new” (post-1990) } \\
\text { medications used } \\
\text { (N_RX_NEW) }\end{array}$ & 3.63 & 2.33 & 0 & 16 \\
\hline $\begin{array}{l}\text { the total number of } \\
\text { “old” (pre-1991) } \\
\text { medications used } \\
\text { (N_RX_OLD) }\end{array}$ & 5.51 & 3.01 & 0 & 21 \\
\hline
\end{tabular}


Table 4

Number of patients in 2004 National Nursing Home Survey using prescription medicines, by class of drug

\begin{tabular}{|l|r|}
\hline \multicolumn{1}{|c|}{ National Drug Code Directory drug class } & \multicolumn{1}{c|}{ Number of patients } \\
\hline 9 METABOLIC/NUTRIENTS & 10,015 \\
\hline 5 CARDIOVASCULAR-RENAL DRUGS & 9,994 \\
\hline 8 GASTROINTESTINAL AGENTS & 9,635 \\
\hline 6 CENTRAL NERVOUS SYSTEM & 9,322 \\
\hline 17 RELIEF OF PAIN & 8,752 \\
\hline 10 HORMONES/HORMONAL MECHANISMS & 5,648 \\
\hline 4 HEMATOLOGIC AGENTS & 4,844 \\
\hline 13 NEUROLOGIC DRUGS & 3,886 \\
\hline 19 RESPIRATORY TRACT & 2,864 \\
\hline 15 OPHTHALMICS & 2,217 \\
\hline 3 ANTIMICROBIAL AGENTS & 1,928 \\
\hline 14 ONCOLYTICS & 646 \\
\hline 12 SKIN/MUCOUS MEMBRANE & 604 \\
\hline L1 HOMEOPATHIC PRODUCTS & 345 \\
\hline 1 ANESTHETIC DRUGS & 270 \\
\hline 16 OTOLOGICS & 267 \\
\hline 20 UNCLASSIFIED/ MISCELLANEOUS & 206 \\
\hline 18 ANTIPARASITICS & 103 \\
\hline 2 ANTIDOTES & 48 \\
\hline 11 IMMUNOLOGICS & 39 \\
\hline 7 CONTRAST MEDIA/ RADIOPHARMACEUTICAL & 5 \\
\hline
\end{tabular}


Table 5

Top 40 medications used by 2004 National Nursing Home Survey respondents, ranked by number of residents using medication

\begin{tabular}{|c|c|c|c|}
\hline Medication & $\begin{array}{l}\text { No. of } \\
\text { residents }\end{array}$ & $\begin{array}{c}\text { FDA } \\
\text { approval } \\
\text { year }\end{array}$ & $\begin{array}{c}1=\text { priority review; } 0 \\
=\text { standard review }\end{array}$ \\
\hline ACETAMINOPHEN & 4875 & 1968 & 1 \\
\hline ASPIRIN & 4471 & 1950 & 1 \\
\hline FUROSEMIDE & 3942 & 1966 & 1 \\
\hline LEVOTHYROXINE & 2649 & 2000 & 0 \\
\hline CALCIUM CARBONATE & 2082 & 2000 & 0 \\
\hline METOPROLOL & 1900 & 1978 & 1 \\
\hline LISINOPRIL & 1877 & 1987 & 0 \\
\hline CITALOPRAM HYDROBRIMIDE & 1756 & 1998 & 0 \\
\hline DONEPEZIL HCL & 1513 & 1996 & 1 \\
\hline DIGOXIN & 1488 & 1975 & 0 \\
\hline WARFARIN SODIUM & 1404 & 1954 & 0 \\
\hline SERTRALINE & 1365 & 1991 & 0 \\
\hline RANITIDINE & 1337 & 1977 & 0 \\
\hline PANTOPRAZOLE SODIUM & 1277 & 2000 & 0 \\
\hline MIRTAZAPINE & 1236 & 1996 & 0 \\
\hline AMLODIPINE & 1235 & 1992 & 0 \\
\hline CLOPIDOGEL & 1234 & 1997 & 1 \\
\hline HYDROCHLOROTHIAZIDE & 1197 & 1959 & 1 \\
\hline LANSOPRAZOLE & 1187 & 1995 & 0 \\
\hline OLANZAPINE & 1152 & 1996 & 1 \\
\hline RISPERIDONE & 1140 & 1993 & 1 \\
\hline HYDROCODONE BITARTRATE & 1015 & 1943 & 0 \\
\hline ALBUTEROL SULFATE & 1009 & 1982 & 0 \\
\hline ATORVASTATIN CALCIUM & 1002 & 1996 & 1 \\
\hline OMEPRAZOLE & 983 & 1989 & 1 \\
\hline ATENOLOL & 974 & 1981 & 1 \\
\hline LORAZEPAM & 957 & 1977 & 0 \\
\hline CELECOXIB & \begin{tabular}{l|l}
933 \\
\end{tabular} & 1998 & 1 \\
\hline ISOSORBIDE & 887 & 1974 & 0 \\
\hline QUETIAPINE FUMARATE & 854 & 1997 & 0 \\
\hline GABAPENTIN & 842 & 1993 & 1 \\
\hline PAROXETINE HCL & 765 & 1992 & 0 \\
\hline CARBIDOPA & 758 & 1975 & 1 \\
\hline IPRATROPIUM BROMIDE & 758 & 1986 & 1 \\
\hline LEVODOPA & 758 & 1970 & 1 \\
\hline PHENYTOIN & 757 & 1953 & 0 \\
\hline VITAMIN E & 739 & 1953 & 1 \\
\hline FLUTICASONE PROPIONATE & 738 & 1990 & 0 \\
\hline NITROGLYCERIN & 718 & 1981 & 1 \\
\hline DILTIAZEM & 702 & 1982 & 0 \\
\hline
\end{tabular}


Table 6

Sources of payment

\begin{tabular}{|l|r|}
\hline Self/private pay/out-of-pocket & $67.6 \%$ \\
\hline Medicaid & $60.6 \%$ \\
\hline Medicare & $13.0 \%$ \\
\hline Private health insurance & $7.8 \%$ \\
\hline Department of Veterans Affairs & $0.9 \%$ \\
\hline Lifecare & $0.6 \%$ \\
\hline Welfare & $0.6 \%$ \\
\hline Other & $2.1 \%$ \\
\hline
\end{tabular}


Table 7

Ordered probit estimates of eq. (1):

HEALTH $_{\mathrm{i}}=\beta$ VINTAGE $_{\mathrm{i}}+\gamma$ PRIORITY $_{\mathrm{i}}+\pi \mathrm{N}_{-} \mathrm{RX}_{\mathrm{i}}+\rho \mathrm{Z}_{\mathrm{i}}+\varepsilon_{\mathrm{i}}$

\begin{tabular}{|c|c|c|c|c|c|}
\hline Model & Regressor & Estimate & StdErr & ChiSq & ProbChiSq \\
\hline \multicolumn{6}{|c|}{ Dependent variable: No. of ADLs resident could perform independently } \\
\hline $1 \mathrm{a}$ & VINTAGE & 0.010 & 0.002 & 29.027 & 0.000 \\
\hline $1 \mathrm{a}$ & |PRIORITY\% & 0.221 & 0.063 & 12.185 & 0.000 \\
\hline $1 \mathrm{a}$ & N_RX & 0.016 & 0.003 & 23.098 & 0.000 \\
\hline \multicolumn{6}{|c|}{ Dependent variable: Ability to transfer } \\
\hline $1 b$ & VINTAGE & 0.015 & 0.002 & 84.198 & 0.000 \\
\hline $1 \mathrm{~b}$ & PRIORITY\% & 0.230 & 0.057 & 16.041 & 0.000 \\
\hline $1 \mathrm{~b}$ & N_RX & 0.018 & 0.003 & 34.280 & 0.000 \\
\hline \multicolumn{6}{|c|}{ Dependent variable: Ability to dress } \\
\hline$\overline{1 c}$ & VINTAGE & 0.011 & 0.002 & 48.006 & 0.000 \\
\hline $1 \mathrm{c}$ & PRIORITY\% & 0.179 & 0.057 & 9.839 & 0.002 \\
\hline $1 c$ & N_RX & 0.023 & 0.003 & 55.646 & 0.000 \\
\hline \multicolumn{6}{|c|}{ Dependent variable: Ability to eat } \\
\hline $1 \mathrm{~d}$ & VINTAGE & 0.011 & 0.002 & 40.651 & 0.000 \\
\hline $1 d$ & PRIORITY\% & 0.204 & 0.060 & 11.606 & 0.001 \\
\hline $1 \mathrm{~d}$ & N_RX & 0.037 & 0.003 & 126.384 & 0.000 \\
\hline \multicolumn{6}{|c|}{ Dependent variable: Ability to use toilet } \\
\hline $1 \mathrm{e}$ & VINTAGE & 0.013 & 0.002 & 55.714 & 0.000 \\
\hline $1 \mathrm{e}$ & PRIORITY\% & 0.193 & 0.058 & 10.930 & 0.001 \\
\hline $1 \mathrm{e}$ & N_RX & 0.027 & 0.003 & 74.803 & 0.000 \\
\hline \multicolumn{6}{|c|}{ Dependent variable: Ability to bathe } \\
\hline $1 \mathrm{f}$ & VINTAGE & 0.012 & 0.002 & 45.129 & 0.000 \\
\hline $1 \mathrm{f}$ & PRIORITY\% & 0.189 & 0.061 & 9.619 & 0.002 \\
\hline $1 \mathrm{f}$ & N_RX & 0.025 & 0.003 & 59.045 & 0.000 \\
\hline
\end{tabular}

$\mathrm{N}=12,252$. All models include dummy variables for single-year-of-age by sex, race, marital status, veteran status, where the resident lived prior to admission, primary diagnosis at the time of admission, up to 16 diagnoses at the time of the interview, sources of payment, and facility fixed effects.

VINTAGE = weighted mean vintage (FDA approval year) of medications used

PRIORITY\% = fraction of medications used that contained active ingredients approved on a priority-review (as opposed to standard-review) basis

N_RX = the total number of medications used 
Table 8

Estimates of selected coefficients from models with no facility characteristics or fixed effects, models with facility characteristics, and models with facility fixed effects

Ordered probit estimates of eq. (1):

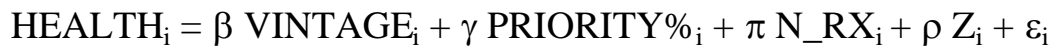

\begin{tabular}{|c|c|c|c|c|c|c|c|}
\hline Model & $\begin{array}{c}\text { Facility } \\
\text { characteristics } \\
\text { included? }\end{array}$ & $\begin{array}{c}\text { Facility } \\
\text { fixed effects } \\
\text { included? }\end{array}$ & Regressor & Estimate & StdErr & ChiSq & ProbChiSq \\
\hline & \multicolumn{7}{|c|}{ Dependent variable: No. of ADLs resident could perform independently } \\
\hline 1 & no & no & VINTAGE & 0.0063 & 0.0016 & 15.19 & 0.0001 \\
\hline 1 & no & no & PRIORITY\% & 0.1651 & 0.0568 & 8.45 & 0.0036 \\
\hline 2 & yes & no & VINTAGE & 0.0067 & 0.0016 & 16.84 & 0.0000 \\
\hline 2 & yes & no & PRIORITY\% & 0.1767 & 0.0569 & 9.65 & 0.0019 \\
\hline 3 & Ino & ves & VINTAGE & 0.0098 & 0.0018 & 29.03 & 0.0000 \\
\hline \multirow[t]{3}{*}{3} & no & yes & PRIORITY\% & 0.2208 & 0.0633 & 12.18 & 0.0005 \\
\hline & \multirow{2}{*}{\multicolumn{7}{|c|}{ Dependent variable: Ability to transfer }} \\
\hline & & & & & & & \\
\hline 4 & no & no & VINTAGE & 0.0113 & 0.0015 & 55.06 & 0.0000 \\
\hline 4 & no & no & PRIORITY\% & 0.2049 & 0.0530 & 14.93 & 0.0001 \\
\hline & & & & & & & \\
\hline 5 & yes & no & VINTAGE & 0.0115 & 0.0015 & 56.82 & 0.0000 \\
\hline 5 & yes & no & PRIORITY\% & 0.2100 & 0.0531 & 15.65 & 0.0001 \\
\hline 6 & no & yes & VINTAGE & 0.0151 & 0.0016 & 84.20 & 0.0000 \\
\hline \multirow[t]{2}{*}{6} & no & yes & PRIORITY\% & 0.2297 & 0.0573 & 16.04 & 0.0001 \\
\hline & \multicolumn{7}{|c|}{ Dependent variable: Ability to dress } \\
\hline 7 & no & no & VINTAGE & 0.0088 & 0.0015 & 34.14 & 0.0000 \\
\hline 7 & no & no & PRIORITY\% & 0.1532 & 0.0528 & 8.41 & 0.0037 \\
\hline 8 & yes & no & VINTAGE & 0.0091 & 0.0015 & 36.13 & 0.0000 \\
\hline 8 & yes & no & PRIORITY\% & 0.1631 & 0.0529 & 9.52 & 0.0020 \\
\hline 9 & lno & Ves & IVINTAGE & 0.0114 & 0.0016 & 48.01 & 0.0000 \\
\hline \begin{tabular}{|l} 
\\
\end{tabular} & no & yes & PRIORITY\% & 0.1794 & 0.0572 & $\begin{array}{ll}40.01 \\
9.84\end{array}$ & 0.0017 \\
\hline & & & & & & & \\
\hline
\end{tabular}

$\mathrm{N}=12,252$. All models include dummy variables for single-year-of-age by sex, race, marital status, veteran status, where the resident lived prior to admission, primary diagnosis at the time of admission, up to 16 diagnoses at the time of the interview, and sources of payment.

Facility characteristics are dummy variables for nursing home ownership type, bedsize, and metropolitan area status.

VINTAGE = weighted mean vintage (FDA approval year) of medications used

PRIORITY\% = fraction of medications used that contained active ingredients approved on a priorityreview (as opposed to standard-review) basis 
Table 8 (continued)

Estimates of selected coefficients from models with no facility characteristics or fixed effects, models with facility characteristics, and models with facility fixed effects

Ordered probit estimates of eq. (1):

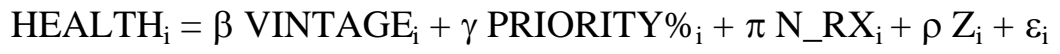

\begin{tabular}{|c|c|c|c|c|c|c|c|}
\hline Model & $\begin{array}{c}\text { Facility } \\
\text { characteristics } \\
\text { included? }\end{array}$ & $\begin{array}{c}\text { Facility } \\
\text { fixed effects } \\
\text { included? }\end{array}$ & $\begin{array}{c}\text { Explanatory } \\
\text { variable }\end{array}$ & Estimate & StdErr & ChiSq & ProbChiSq \\
\hline & \multicolumn{7}{|c|}{ Dependent variable: Ability to eat } \\
\hline 10 & no & no & VINTAGE & 0.0079 & 0.0016 & 25.23 & 0.0000 \\
\hline 10 & no & no & PRIORITY\% & 0.2055 & 0.0546 & 14.17 & 0.0002 \\
\hline 11 & yes & no & VINTAGE & 0.0082 & 0.0016 & 27.04 & 0.0000 \\
\hline 11 & yes & no & PRIORITY\% & 0.2139 & 0.0546 & 15.33 & 0.0001 \\
\hline 12 & no & yes & VINTAGE & 0.0110 & 0.0017 & 40.65 & 0.0000 \\
\hline \multirow[t]{3}{*}{12} & no & yes & PRIORITY\% & 0.2038 & 0.0598 & 11.61 & 0.0007 \\
\hline & & & & & & & \\
\hline & \multicolumn{7}{|c|}{ Dependent variable: Ability to use toilet } \\
\hline 13 & no & no & VINTAGE & 0.0095 & 0.0015 & 38.51 & 0.0000 \\
\hline 13 & no & no & PRIORITY\% & 0.1742 & 0.0537 & 10.52 & 0.0012 \\
\hline & & & & & & & \\
\hline 14 & yes & no & VINTAGE & 0.0098 & 0.0015 & 40.36 & 0.0000 \\
\hline 14 & yes & no & PRIORITY\% & 0.1822 & 0.0538 & 11.48 & 0.0007 \\
\hline 15 & Ino & Ves & VINTAGE & 00125 & 0.0017 & 5571 & 0.0000 \\
\hline \multirow[t]{2}{*}{15} & no & yes & PRIORITY\% & 0.1928 & 0.0583 & 10.93 & 0.0009 \\
\hline & \multicolumn{7}{|c|}{ Dependent variable: Ability to bathe } \\
\hline 16 & no & no & VINTAGE & 0.0076 & 0.0016 & 23.39 & 0.0000 \\
\hline 16 & no & no & PRIORITY\% & 0.1434 & 0.0553 & 6.73 & 0.0095 \\
\hline & & & & & & & תחתח \\
\hline 17 & yes & no & VINTAGE & 0.0079 & 0.0016 & 24.80 & 0.0000 \\
\hline 17 & yes & no & PRIORITY\% & 0.1506 & 0.0553 & 7.41 & 0.0065 \\
\hline & & & & & & & \\
\hline 18 & no & yes & VINTAGE & 0.0117 & 0.0017 & 45.13 & 0.0000 \\
\hline 18 & no & yes & PRIORITY\% & 0.1892 & 0.0610 & 9.62 & 0.0019 \\
\hline
\end{tabular}

$\mathrm{N}=12,252$. All models include dummy variables for single-year-of-age by sex, race, marital status, veteran status, where the resident lived prior to admission, primary diagnosis at the time of admission, up to 16 diagnoses at the time of the interview, and sources of payment.

Facility characteristics are dummy variables for nursing home ownership type, bedsize, and metropolitan area status.

VINTAGE = weighted mean vintage (FDA approval year) of medications used

PRIORITY\% = fraction of medications used that contained active ingredients approved on a priorityreview (as opposed to standard-review) basis 
Table 9

Ordered probit estimates of eq. (2):

HEALTH $_{i}=\beta_{1}$ POST1980 $_{i}+\beta_{2}$ POST $1990 \%_{i}+\gamma$ PRIORITY\% $_{i}+\pi N_{-}$RX $_{i}+\rho Z_{i}+\varepsilon_{i}$

\begin{tabular}{|c|c|c|c|c|c|}
\hline Model & Regressor & Estimate & StdErr & ChiSq & ProbChiSq \\
\hline \multicolumn{6}{|c|}{ Dependent variable: No. of ADLs resident could perform independently } \\
\hline $2 \mathrm{a}$ & POST1980\% & 0.181 & 0.082 & 4.845 & 0.028 \\
\hline $2 \mathrm{a}$ & POST1990\% & 0.341 & 0.083 & 17.039 & 0.000 \\
\hline $2 \mathrm{a}$ & PRIORITY\% & 0.271 & 0.063 & 18.460 & 0.000 \\
\hline $2 \mathrm{a}$ & N_RX & 0.017 & 0.003 & 24.847 & 0.000 \\
\hline & & & & & \\
\hline \multicolumn{6}{|c|}{ Dependent variable: Ability to transfer } \\
\hline $2 \mathrm{~b}$ & POST1980\% & 0.300 & 0.075 & 16.046 & 0.000 \\
\hline $2 \mathrm{~b}$ & POST1990\% & 0.417 & 0.076 & 30.473 & 0.000 \\
\hline $2 \mathrm{~b}$ & PRIORITY\% & 0.276 & 0.057 & 23.346 & 0.000 \\
\hline $2 \mathrm{~b}$ & N_RX & 0.019 & 0.003 & 35.965 & 0.000 \\
\hline & & & & & \\
\hline \multicolumn{6}{|c|}{ Dependent variable: Ability to dress } \\
\hline $2 \mathrm{c}$ & POST1980\% & 0.154 & 0.075 & 4.255 & 0.039 \\
\hline $2 \mathrm{C}$ & POST1990\% & 0.421 & 0.075 & 31.287 & 0.000 \\
\hline 2c & PRIORITY\% & 0.226 & 0.057 & 15.676 & 0.000 \\
\hline 2c & N_RX & 0.024 & 0.003 & 58.024 & 0.000 \\
\hline \multirow{2}{*}{\multicolumn{6}{|c|}{ Dependent variable: Ability to eat }} \\
\hline $2 \mathrm{~d}$ & POST1980\% & 0207 & & & \\
\hline $2 \mathrm{~d}$ & POST1990\% & & & & \\
\hline 29 & & & & & \\
\hline $2 \mathrm{~d}$ & PRIORITY\% & 0.270 & 0.060 & 20.480 & 0.000 \\
\hline $2 \mathrm{~d}$ & N_RX & 0.038 & 0.003 & 130.147 & 0.000 \\
\hline \multicolumn{6}{|c|}{ Dependent variable: Ability to use toilet } \\
\hline $2 \mathrm{e}$ & POST1980\% & 0.225 & 0.076 & 8.716 & 0.003 \\
\hline $2 \mathrm{e}$ & POST1990\% & 0.399 & 0.077 & 27.009 & 0.000 \\
\hline $2 \mathrm{e}$ & PRIORITY\% & 0.242 & 0.058 & 17.268 & 0.000 \\
\hline $2 \mathrm{e}$ & N_RX & 0.028 & 0.003 & 77.833 & 0.000 \\
\hline \multicolumn{6}{|c|}{ Dependent variable: Ability to bathe } \\
\hline $2 \mathrm{f}$ & POST1980\% & 0.202 & 0.080 & 6.465 & 0.011 \\
\hline $2 \mathrm{f}$ & POST1990\% & 0.337 & 0.080 & 17.769 & 0.000 \\
\hline $2 \mathrm{f}$ & PRIORITY\% & 0.221 & 0.061 & 13.187 & 0.000 \\
\hline $2 \mathrm{f}$ & N_RX & 0.026 & 0.003 & 60.725 & 0.000 \\
\hline
\end{tabular}

$\mathrm{N}=12,252$. All models include dummy variables for single-year-of-age by sex, race, marital status, veteran status, where the resident lived prior to admission, primary diagnosis at the time of admission, up to 16 diagnoses at the time of the interview, sources of payment, and facility fixed effects.

POST1980\% = fraction of medications used that contained active ingredients approved after 1980

POST1990\% = fraction of medications used that contained active ingredients approved after 1990

PRIORITY\% = fraction of medications used that contained active ingredients approved on a priority-review (as opposed to standard-review) basis

N_RX = the total number of medications used 
Table 10

Ordered probit estimates of eq. (3):

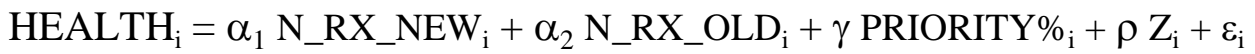

\begin{tabular}{|l|l|l|l|l|l|}
\hline Model & Regressor & Estimate & StdErr & ChiSq & ProbChiSq \\
\hline
\end{tabular}

\begin{tabular}{|c|c|c|c|c|c|}
\hline \multicolumn{6}{|c|}{ Dependent variable: No. of ADLs resident could perform independently } \\
\hline За & N_RX_NEW & 0.047 & 0.006 & 70.139 & 0.000 \\
\hline $3 \mathrm{a}$ & N_RX_OLD & -0.005 & 0.004 & 1.121 & 0.290 \\
\hline За & PRIORITY\% & 0.208 & 0.061 & 11.532 & 0.001 \\
\hline \multicolumn{6}{|c|}{ Dependent variable: Ability to transfer } \\
\hline $3 \mathrm{~b}$ & N_RX_NEW & 0.064 & 0.005 & 149.054 & 0.000 \\
\hline $3 b$ & N_RX_OLD & -0.013 & 0.004 & 9.422 & 0.002 \\
\hline $3 \mathrm{~b}$ & PRIORITY\% & 0.197 & 0.055 & 12.571 & 0.000 \\
\hline \multicolumn{6}{|c|}{ Dependent variable: Ability to dress } \\
\hline $3 c$ & N_RX_NEW & 0.062 & 0.005 & 141.171 & 0.000 \\
\hline $3 c$ & N_RX_OLD & -0.003 & 0.004 & 0.491 & 0.484 \\
\hline $3 c$ & PRIORITY\% & 0.170 & 0.055 & 9.388 & 0.002 \\
\hline \multicolumn{6}{|c|}{ Dependent variable: Ability to eat } \\
\hline $3 d$ & N_RX_NEW & 0.077 & 0.006 & 187.112 & 0.000 \\
\hline $3 d$ & N_RX_OLD & 0.011 & 0.004 & 6.409 & 0.011 \\
\hline $3 d$ & PRIORITY\% & 0.197 & 0.058 & 11.614 & 0.001 \\
\hline \multicolumn{6}{|c|}{ Dependent variable: Ability to use toilet } \\
\hline $3 e$ & N_RX_NEW & 0.066 & 0.005 & 153.927 & 0.000 \\
\hline $3 e$ & N_RX_OLD & 0.001 & 0.004 & 0.095 & 0.758 \\
\hline 3e & PRIORITY\% & 0.169 & 0.056 & 8.980 & 0.003 \\
\hline \multicolumn{6}{|c|}{ Dependent variable: Ability to bathe } \\
\hline $3 f$ & N_RX_NEW & 0.057 & 0.006 & 105.978 & 0.000 \\
\hline $3 f$ & N_RX_OLD & 0.004 & 0.004 & 0.787 & 0.375 \\
\hline $3 f$ & PRIORITY\% & 0.153 & 0.059 & 6.716 & 0.010 \\
\hline
\end{tabular}

$\mathrm{N}=12$,252. All models include dummy variables for single-year-of-age by sex, race, marital status, veteran status, where the resident lived prior to admission, primary diagnosis at the time of admission, up to 16 diagnoses at the time of the interview, sources of payment, and facility fixed effects.

PRIORITY\% = fraction of medications used that contained active ingredients approved on a priority-review (as opposed to standard-review) basis

N_RX_NEW = the total number of "new" (post-1990) medications used

N_RX_OLD = the total number of "old” (pre-1991) medications used 
Table 11

Ordered probit estimates of eq. (3), for 5 largest drug classes:

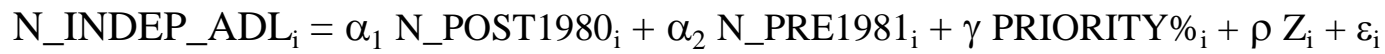

\begin{tabular}{|c|c|c|c|c|c|}
\hline Model & Regressor & Estimate & StdErr & ChiSq & ProbChiSq \\
\hline & \multicolumn{5}{|c|}{ ALL MEDICATIONS $(\mathrm{N}=12,252)$} \\
\hline 1 & No. of post-1980 medications & 0.0597 & 0.0054 & 120.61 & 0.0000 \\
\hline 1 & No. of pre-1981 medications & -0.0067 & 0.0061 & 1.20 & 0.2733 \\
\hline \multirow[t]{2}{*}{1} & $\%$ of meds. that were priority-review & 0.2011 & 0.0613 & 10.76 & 0.0010 \\
\hline & \multicolumn{5}{|c|}{ METABOLIC/NUTRIENTS $(\mathrm{N}=4546)$} \\
\hline 2 & No. of post-1980 medications & 0.1443 & 0.0441 & 10.70 & 0.0011 \\
\hline 2 & No. of pre-1981 medications & 0.0083 & 0.0489 & 0.03 & 0.8656 \\
\hline \multirow[t]{2}{*}{2} & $\%$ of meds. that were priority-review & 0.1512 & 0.0593 & 6.49 & 0.0108 \\
\hline & \multicolumn{5}{|c|}{ CARDIOVASCULAR-RENAL DRUGS (N = 9003) } \\
\hline 3 & No. of post-1980 medications & 0.0866 & 0.0164 & 27.75 & 0.0000 \\
\hline 3 & No. of pre-1981 medications & 0.0303 & 0.0163 & 3.47 & 0.0624 \\
\hline \multirow[t]{2}{*}{3} & $\%$ of meds. that were priority-review & 0.0619 & 0.0396 & 2.45 & 0.1177 \\
\hline & \multicolumn{5}{|c|}{ GASTROINTESTINAL AGENTS $(\mathrm{N}=6444)$} \\
\hline 4 & No. of post-1980 medications & 0.0241 & 0.0342 & 0.50 & 0.4807 \\
\hline 4 & No. of pre-1981 medications & -0.0886 & 0.0394 & 5.05 & 0.0246 \\
\hline \multirow[t]{2}{*}{4} & $\%$ of meds. that were priority-review & 0.0174 & 0.0486 & 0.13 & 0.7201 \\
\hline & \multicolumn{5}{|c|}{ CENTRAL NERVOUS SYSTEM DRUGS ( $\mathrm{N}=8539)$} \\
\hline 5 & No. of post-1980 medications & 0.0476 & 0.0184 & 6.71 & 0.0096 \\
\hline 5 & No. of pre-1981 medications & -0.0016 & 0.0318 & 0.00 & 0.9602 \\
\hline \multirow[t]{2}{*}{5} & $\%$ of meds. that were priority-review & 0.0132 & 0.0394 & 0.11 & 0.7367 \\
\hline & \multicolumn{5}{|c|}{ RELIEF OF PAIN DRUGS $(\mathrm{N}=7253)$} \\
\hline 6 & No. of post-1980 medications & 0.1293 & 0.0400 & 10.44 & 0.0012 \\
\hline 6 & No. of pre-1981 medications & 0.1043 & 0.0314 & 11.01 & 0.0009 \\
\hline 6 & $\%$ of meds. that were priority-review & 0.1533 & 0.0670 & 5.23 & 0.0221 \\
\hline
\end{tabular}

N_INDEP_ADL $=$ the number of ADLs the resident could perform independently

All models include dummy variables for single-year-of-age by sex, race, marital status, veteran status, where the resident lived prior to admission, primary diagnosis at the time of admission, up to 16 diagnoses at the time of the interview, sources of payment, and facility fixed effects. 
Table 12

Average annual rate of decline of functional limitations due to pharmaceutical innovation, 1990-2004

\begin{tabular}{|l|c|}
\hline Activity & $\begin{array}{c}\text { average annual rate of decline of functional limitation } \\
\text { due to pharmaceutical innovation, 1990-2004 }\end{array}$ \\
\hline Transferring & $2.10 \%$ \\
\hline Dressing & $1.70 \%$ \\
\hline Eating & $2.10 \%$ \\
\hline Using the toilet & $1.60 \%$ \\
\hline Bathing & $1.20 \%$ \\
\hline
\end{tabular}




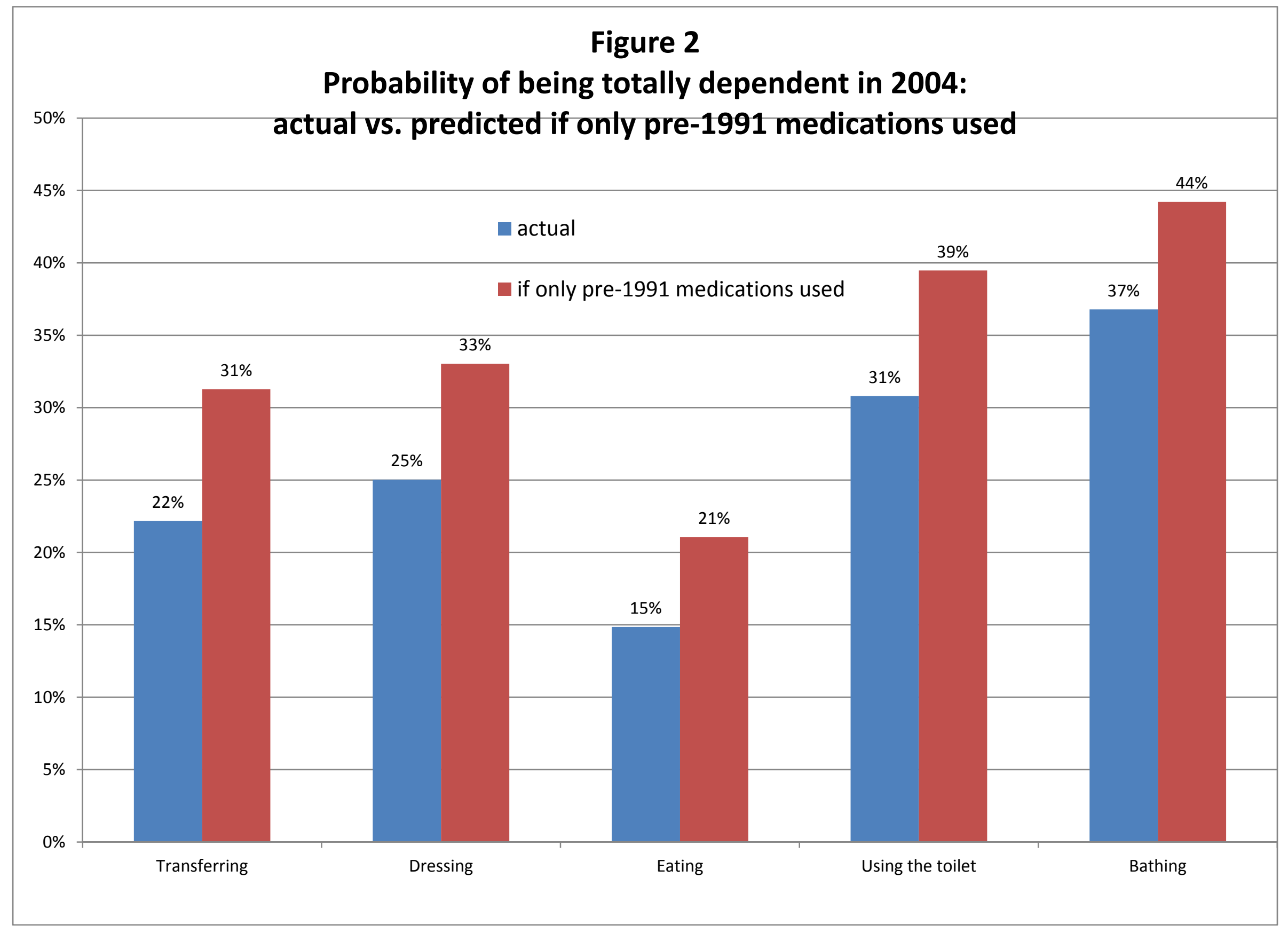

